\title{
Structurally Integrated Slotless PM Brushless Motor with Spiral Wound Laminations for Marine Thrusters
}

\author{
Shu Hau Lai, Suleiman Abu Sharkh \\ School of Engineering Sciences, University of Southampton, Highfield, Southampton SO17 1BJ, UK \\ T: 02380593397, F: 02380593053, E: suleiman@soton.ac.uk
}

Keywords: slotless brushless PM motor, helical stator laminations, rim-driven thrusters, integrated thrusters.

\begin{abstract}
Rim driven thrusters with structurally integrated brushless PM motors are now an established technology with an increasing range of applications. In these thrusters, the stator of the motor is housed within the thruster duct, and the rotor forms a ring around the tips of the propeller. Such high pole number motors tend to be very thin radialy, have very small length to diameter ratios, and have relatively large airgaps to accommodate corrosion protection layers on the surfaces of the rotor and stator. The relatively large diameter stator laminations of such machines tend therefore to have very thin back of core and narrow teeth, which make them expensive and difficult to manufacture. This paper proposes an alternative potentially lower cost motor topology featuring a slotless stator whose laminations are manufactured from a single strip of steel that is edge wound into a spiral (like a "slinky" and then fitted over the windings that are preformed on the outside surface of a non-conducting former. The former is also part of the sealed housing that protects the stator from corrosion in seawater. The paper discusses the design optimisation of such a motor using analytical and finite element analysis (FEA), describes a demonstrator motor and reports experimental and FEA results.
\end{abstract}

\section{Introduction}

Marine thrusters with structurally integrated electric motors such as those shown in Figs. 1 and 2 have been the subject of significant research and development in recent years for a wide range of applications. Small thrusters (up to $300 \mathrm{~mm}$ prop dia, $15 \mathrm{~kW}$ ) primarily for remotely operated and autonomous underwater vehicles were developed by the Authors and are now commercially available [1, 2, 3]. Podded rim driven thrusters with $\mathrm{MW}$ ratings are also under development by General Dynamics Electric Boat for large manned submarines and ship propulsion [9, 10]. Recently, Rolls-Royce announced the development of a tunnel rim driven thruster for offshore support vessels and other types of marine propulsor $[8,13]$. In these ducted propeller thrusters, the stator of the motor is integrated within the structure of the duct, while the rotor forms a ring around the propeller rim (hence sometimes known as rim or tip driven thrusters), thus resulting in a compact unit, compared to ducted thrusters with hub electric motors, with comparable efficiency. Such a configuration is also suitable for other applications such as marine turbine generators [4], fans and pumps.

Although the concept of such a thruster was proposed early in the $20^{\text {th }}$ century [7], actual practical realisation of an efficient compact device has become possible only relatively recently, when high-energy permanent magnet materials became available. Early demonstrators of such a concept used induction motor (IM) [5] and switched reluctance motors (SRM) with part stators [11]. But these demonstrators suffered from having relatively thick rotors and stators, and hence relatively thick ducts with high drag losses, which impair hydrodynamic efficiency at high vessel advance speeds. The performance of IM and SRM also tends to be inferior due to the large airgap needed to incorporate corrosion protection layers on the surfaces of the rotor and stator. A permanent magnet machine is however more tolerant of large gaps, and can be designed to have a large number of poles, thus resulting in relatively very thin rotors and stators, yet maintaining good machine efficiency [1].

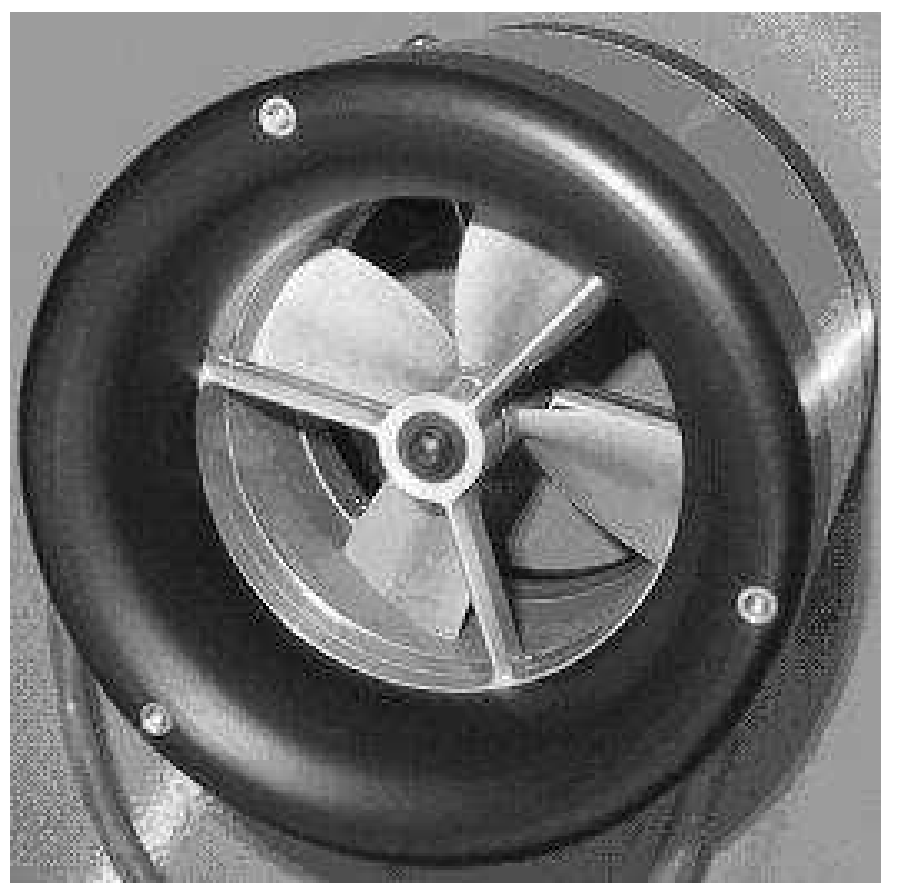

Fig. 1: Photograph of a commercial rim-driven thruster designed by the Authors 


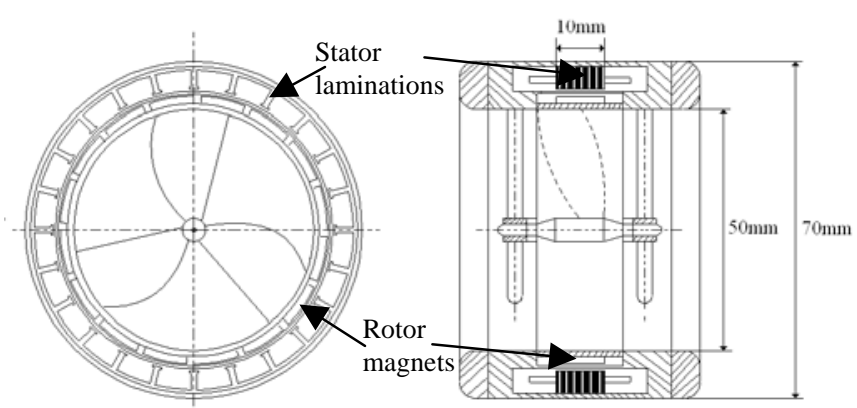

Fig. 2: A drawing of a thruster designed by the Authors[1]

However, the extremely thin stators and rotors of such motors pose many practical manufacturing difficulties, which increases the cost of the machine. The $50 \mathrm{~mm}$ propeller diameter thruster shown in Fig. 2 for example [1] has lamination yoke thickness of $1.25 \mathrm{~mm}$ and teeth that are only $1.5 \mathrm{~mm}$ wide. This makes lamination production and handling challenging, and costly.

This paper discusses the design optimisation and production of an alternative motor topology that is potentially cheaper to manufacture. The motor features a slotless stator whose laminations are manufactured from a single strip of steel that is helically edge wound (like a Slinky). Stator coils are wound on the outside of a non-conducting former, a process that can be easily automated with additional cost savings. The paper also presents finite element analysis and experimental results for a demonstrator motor.

\section{Methodology}

The design optimisation procedure of such a motor was as described in [1, 2]. For given thrust output and propeller diameter, motor torque and speed are determined based on combined hydrodynamic and electromagnetic studies. It is vital that the electric motor characteristics are matched to propeller hydrodynamic characteristics to maximize overall efficiency. Hydrodynamic efficiency also dictates a thin short duct, which limits the available space for the motor.

An analytical method was used to optimise the design of the motor. The airgap flux was determined by solving the Laplace's and Poisson's equations of the scalar magnetic potentials $\varphi_{I}$ and $\varphi_{I I}$ in the airgap and magnets, respectively, as described in [12], assuming parallel magnetised magnets:

$$
\begin{array}{ll}
\nabla^{2} \varphi_{I}=0 & \text { in the airgap } \\
\nabla^{2} \varphi_{I I}=\frac{1}{\mu_{r}} \nabla . \mathbf{M} & \text { in the magnets }
\end{array}
$$

where $\mathbf{M}$ is the magnetisation vector of the magnets and $\mu_{r}$ is the relative permeability of the magnets. The magnetic field vectors in the gap are calculated in the usual manner:

$$
\begin{aligned}
& \mathbf{H}_{I}=-\nabla \varphi_{I} \\
& \mathbf{B}_{I}=\mu_{o} \mathbf{H}_{I}
\end{aligned}
$$

Torque exerted on the rotor due to the interaction of stator current and rotor magnetic filed is given by:

$$
T=-L \int_{A} \mathbf{r} \times\left(\mathbf{J} \times \mathbf{B}_{I}\right) d A
$$

Where $\mathbf{J}$ denotes the winding current density vector in the area $A$ and $L$ is the active length of the machine. Ideal squarewave current is assumed for the purpose of the analytical optimisation studies. Copper losses are calculated in the usual manner and iron losses are estimated from empirical data for the material used.

For given available motor volume and current density, maximum efficiency is determined by two main parameters, namely magnet thickness and the number of poles. Arguably, current density is also another parameter that is determined by the degree of cooling, which is a function of the thickness of the windings, but for feasible designs for the machine under study this maximum permissible current density is almost constant. The analytical approach described above was used to analyse candidate motor designs, to identify a range of magnet thickness and pole numbers of feasible designs (designs that fit within the available space). In all of the designs a steel working flux density of $1.5 \mathrm{~T}$ was assumed.

Feasible designs were further analysed using two-dimensional transient finite element analysis incorporating rotor motion and external 3-phase inverter circuit as described in [1]. Fig. 3 shows flux distribution in a two-pole section of a candidate motor design.

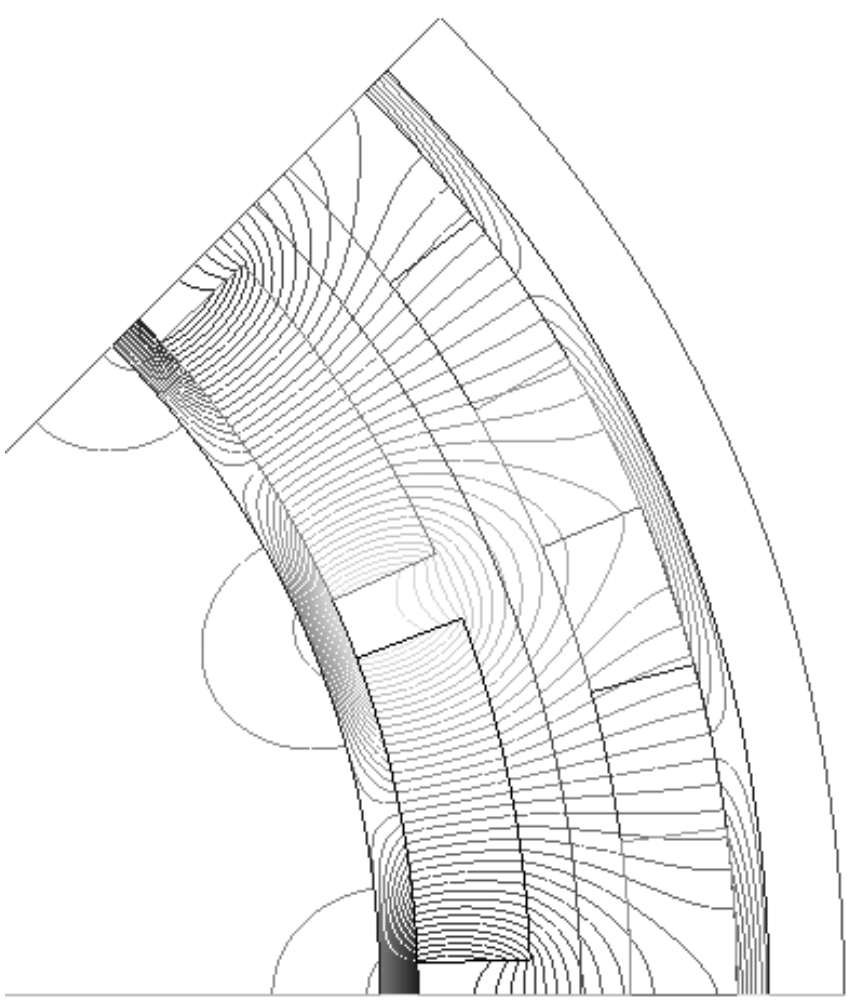

Fig. 3: FEA flux distribution in a candidate motor design 
Fig. 4 shows a plot of efficiency versus magnet length for different number of poles Np. Below 14 poles, the designs are not feasible; i.e. do not fit within the available volume: the endwinding is too long and/or the space available for the winding is too small. Having a high pole number is essential for such a motor. For a given number of poles, the efficiency of the motor initially increases as the magnet thickness and magnetic flux increase; approaching a maximum at about 5 $\mathrm{mm}$. Further increase in magnet thickness results in a decrease in efficiency due to the reduction in space available for stator windings. Also in general for a given magnet thickness, motor efficiency also approaches a maximum at a certain number of poles, before falling again as the number of poles increases, due to increase of the proportion of flux leakage between neighbouring magnets, and increased of fundamental motor frequency, and associated increase of core and switching losses.

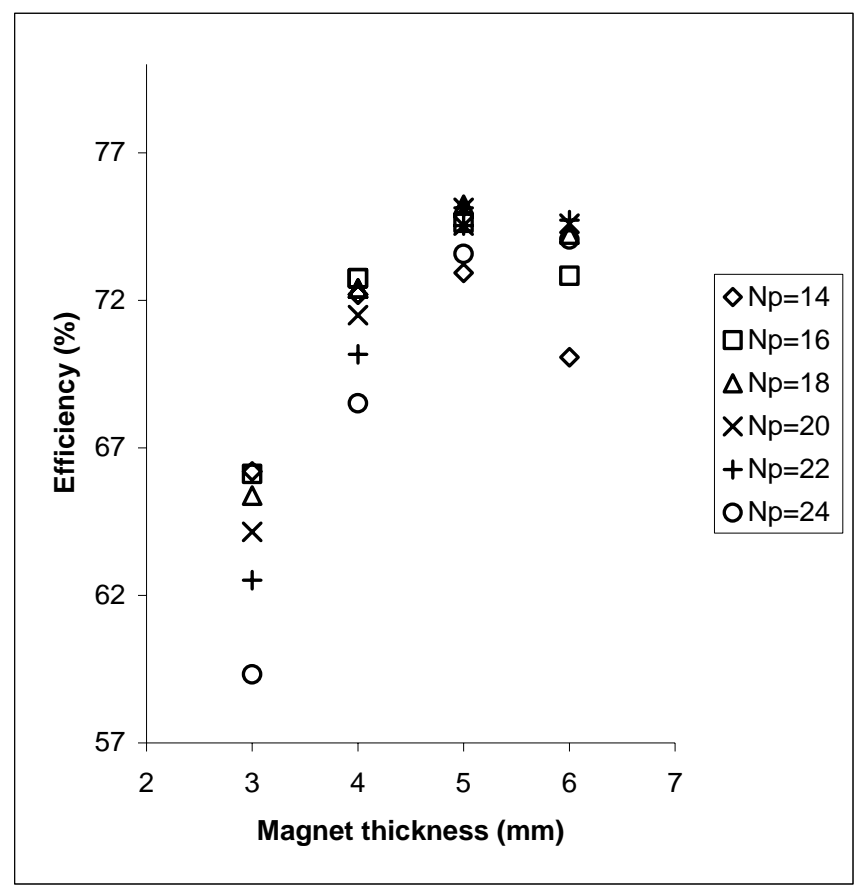

Fig. 3: Efficiency versus magnet thickness and number of poles

Fig. 3 suggests that maximum efficiency is achieved for the combination of magnet thickness of $5 \mathrm{~mm}$ and pole number of 20 poles. However, practical constraints on minimum manufacturable stator and rotor yoke thicknesses, combined with constraints on overall cost and size of magnets and rotor moment of inertia resulted in practice in a choice of 16 poles and $4.5 \mathrm{~mm}$ thick magnets.

\section{Description of the demonstrator motor}

Table 1 presents a summary of principal motor parameters as manufactured. A photograph of the motor components before assembly is shown in Fig. 4. The stator windings were wound on a former made of non-conducting, non-magnetic material with suitable thermal and mechanical properties. The former outer surface was machined to have slots to guide the windings. The former also functions as part of a water-sealed housing system for the stator.

The stator laminations were formed from a single strip of steel of $0.5 \mathrm{~mm}$ thick and $1.25 \mathrm{~mm}$ wide. The strip was edge wound under tension on a mandrel that was smaller in diameter than the final diameter of the helical lamination. A helical thread-like groove was machined on the surface of the mandrel to guide the steel strip and prevent it from its natural tendency to bend flat. The wound strip was left on the mandrel for several hours to even stress distribution, before removing it from the threaded small diameter mandrel and clamping it on a mandrel of the correct larger diameter. The whole assembly was then normalised at high temperature.

The helical laminations were then fitted and tightened over the slot liner covering the windings. Insulating varnish was subsequently applied to glue the assembly of laminations and windings and improve thermal conductivity. The whole assembly is then sealed in an aluminium shroud, which forms the outer surface of the thruster and supports the bearing assembly spider. The propeller is fitted inside the rotor ring and the whole rotor assembly is potted in epoxy.

\begin{tabular}{|l|l|}
\hline Motor parameter & Value \\
\hline Stator steel thickness & $1.25 \mathrm{~mm}$ \\
\hline Rotor steel thickness & $1.5 \mathrm{~mm}$ \\
\hline Number of poles & 16 \\
\hline Magnet thickness & $4.5 \mathrm{~mm}$ \\
\hline Motor axial length & $25 \mathrm{~mm}$ \\
\hline Stator OD & $104 \mathrm{~mm}$ \\
\hline Rotor ID & $73 \mathrm{~mm}$ \\
\hline Electromagnetic airgap & $4 \mathrm{~mm}$ \\
\hline Nominal torque & $0.68 \mathrm{Nm}$ \\
\hline Nominal speed & $3600 \mathrm{rmm}$ \\
\hline
\end{tabular}

Table 1: Slotless motor parameters

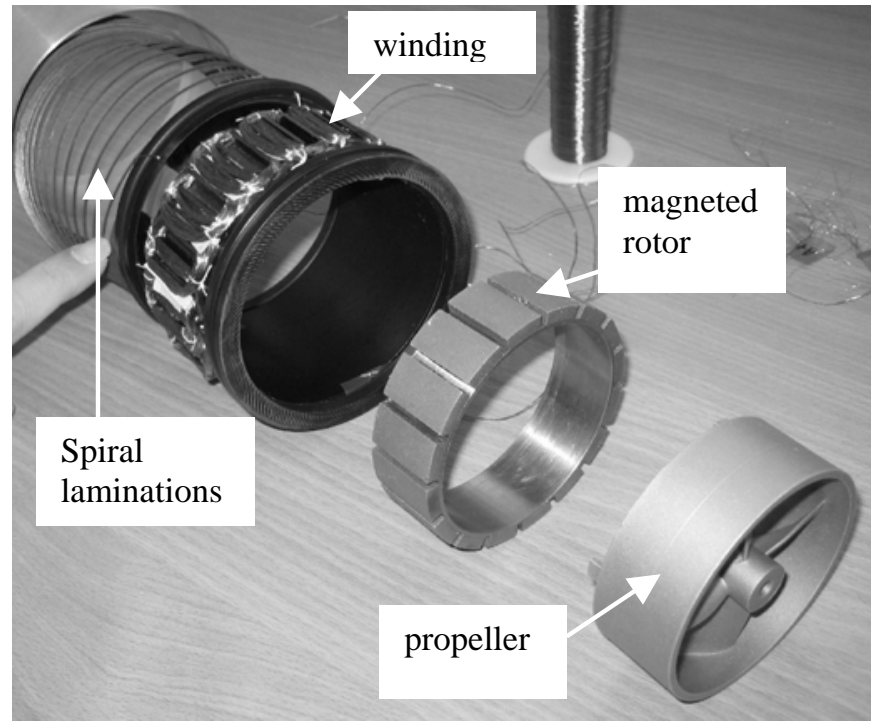

Fig. 4: Photograph of motor before assembly 


\section{Test results}

Preliminary experimental testing was carried out on the demonstrator motor using a general-purpose dynamometer rig. As water-cooling was not available, it was not possible to load the motor to its thermal limit. The tests carried out were sufficient to provide validation for the results obtained from finite element analysis, as well as provide an initial observation on the motor's characteristics. Further tests remain to be made, however, to fully characterise the motor as well as to test its performance as a drive for a rim-driven thruster. These results will be reported in a future paper.

Fig. 5 shows a comparison of the back-EMF waveforms vs rotor position obtained from both experimental and finite element analysis. Fig. 6 shows both experimental and finite element torque vs current characteristics. A good agreement between finite element and experimental results is observed.

Based on finite element results, it is expected that the fullload efficiency of the motor and drive will be about 75\%. A sub-optimal slotted motor that fits in the same volume using thinner magnets has an efficiency of $82 \%$. An optimised version of the slotted motor is expected to achieve an efficiency of just over $85 \%$, i.e. $10 \%$ higher than the slotless motor. In addition to the higher efficiency, the optimised slotted motor magnet volume is $15 \%$ less than that of the slotless motor.

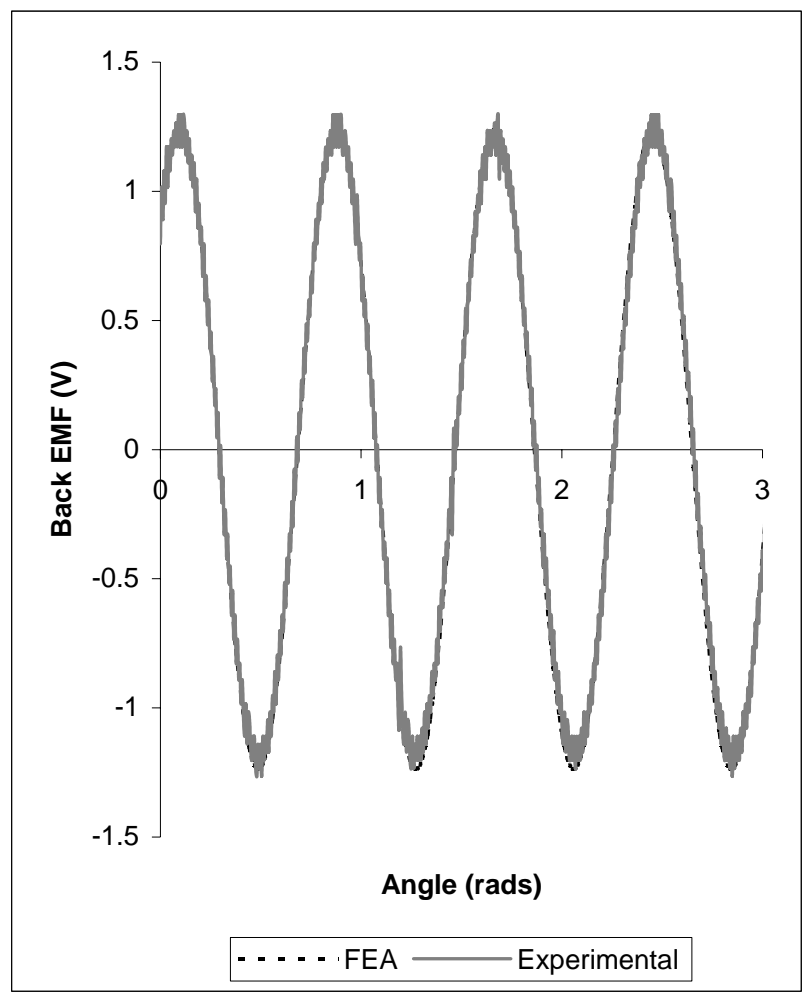

Fig. 5: Back EMF waveforms from FEA and experimental

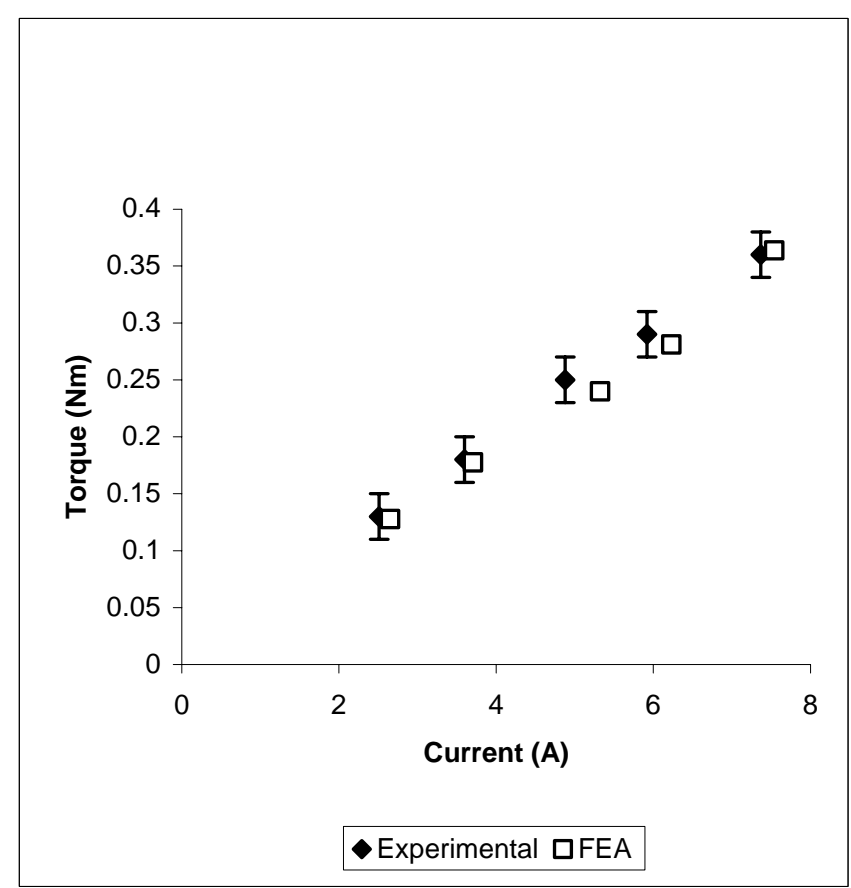

Fig. 6: Torque versus current characteristics

\section{Conclusions}

Rim driven thrusters with structurally integrated motors are now an established technology, with an increasing number of applications. The technology of structurally integrated electric machines is also likely to find applications in other areas such as marine current turbines, pumps and fans.

Such machines tend to have large airgaps, short axial length large diameter to length ratios, and large inner rotor diameter. As a result slotted versions of these machines tend to have very thin stator yokes and teeth, and therefore tend to be challenging and expensive to manufacture and handle.

This paper proposed an alternative potentially lower cost motor topology featuring a slotless stator whose laminations are manufactured from a single strip of steel that was edge wound into a spiral and then fitted over the windings that were preformed on the outside surface of a non-conducting former. The former was also part of the sealed housing that protects the stator from corrosion in seawater. The paper discussed the design optimisation of such a motor using analytical and finite element analysis, described a demonstrator motor and reported experimental and finite element results, which showed good agreement.

The results show that compared to a slotted machine in the same volume, the slotless machine favours having thicker magnets, which increases magnet cost. More crucially, the slotless machine was found to be $10 \%$ less efficient than an optimised slotted machine in the same volume.

Full performance cost evaluation of the two machines is yet to be completed, but early indications suggest significant 
lamination cost saving and a marginal increase of fitted magnet cost. For applications where cost and not efficiency is the overriding objective, the slotless design may be attractive.

\section{Acknowledgements}

The Authors wish to thank Subsea 7, and Mr Ian Edwards in particular for supporting the work presented in this paper.

\section{References}

[1] S. M. Abu Sharkh, S. H. Lai and S. R. Turnock, "A Structurally Integrated Brushless PM Motor for Miniature Propeller Thrusters”, IEE Proc.-Electr Power Appl, 151 (5), pp. 513-519, (2004).

[2] S. M. Abu Sharkh, A. Hughes and S. R. Turnock, "Design and performance of an electric tip-driven thrusters", Proc. Instn Mech. Engrs M: J. Engineering for the Marine Environment, 127, pp. 133-147 (2003)

[3] S. M. Abu Sharkh, "Propulsion for AUVs", in Griffiths, G (Ed.), Technology and Applications of Autonomous underwater vehicles, Taylor and Francis (2003).

[4] S. M. Abu Sharkh, D. Morris, L. Mayer, S. R. Turnock, and A. S. Bahaj, "Performance of an integrated water turbine PM generator”, IEE PEMD Conf., Bath, pp. 486-489, (2002).

[5] D. W. Brown, J. R. Repp, O. S. Taylor, 'Submersible outboard electric motor/propulsor’, Nav. Eng. J., 101, pp. 4452 (1989).
[6] J. K. Holt and G. C. Kennedy, "Propulsion systems for submarine vessels”, US Patent 5306183, (1994).

[7] L. Kort, "Elektrisch angertriebene Schiffsschraube", German Patent No 688114, (1940).

[8] O. Krovel, R. Nilssen, S. E. Skaar, E. Lovli, N. Sandoy, "Design of an integrated $100 \mathrm{~kW}$ Permanent Magnet Synchronous machine in a prototype thrusters for ship propulsion”,International Conference on Electrical Machines ICEM2004, Cracow, Poland, pp.117-118 (2004).

[9] M. Lea, D. Thompson, B. Van Blarcom, J. Eaton, J. Friesch, J. Richards, “ Scale model testing of a commercial rim driven propulsor pod”, Journal of Ship Production, 19 (2), pp. 121-130, (2004).

[10] J. Richards, 'Further development in pod propulsion,' New Wave, 1, p. 4. (2003).

[11] K. M. Richardson, C. Pollock, and J. O. Flower, "Design of a Switched Reluctance Motor for an Integrated Motor/Propeller Unit”, Proceedings from the IEE Seventh International Conference on Electrical Machines and Drives, Durham, pp. 271-275, (1995).

[12] Z. Q. Zhu, D. Howe, C. C. Chan, "Improved analytical model for predicting the magnetic field distribution in brushless permanent magnet machines", IEEE Trans. Magn., , 38 (1), pp. 152-158 (2002).

[13] "Rolls-Royce introduces Rim Drive thruster technology", Press release published on http://www.rollsroyce.com/marine/overview/news/2005/newsitem12.htm, 15 Nov (2005). 